Indonesian Journal of Islamic Communication, Vol. 1, No. 2, Desember 2018: 36-49

\title{
HERMENEUTIKA KOMUNIKATIF AMINA WADUD MUHSIN
}

\author{
Labibul Wildan \\ Pakar Hermeneutika
}

Diunggah 1 Oktober / Direvisi 23 November / Diterima 29 Desember 2018

\begin{abstract}
Abstrac: This study describes Amina Wadud's offer of the hermeneutics method of the Qur'an as one form of interpretation method to obtain conclusions on the meaning of a text or verse. In the general hermeneutics framework, Amina Wadud was explained, an interpreter must always connect three aspects of interpreting: first, in the context of what the text was written, if it is related to the Qur'an, then in the context of whether the verse was revealed. Second, what is the composition of the grammar of the text (verse), how is the expression, what is said. And the third, how is the whole text (verse), weltanchaung or view of his life. The hermeneutic pattern chosen by Amina Wadud was elaborated through this framework, so that each verse that was to be interpreted was analyzed according to certain steps. Amina Wadud wants women in Islam to be placed on an equal footing with men, by looking at contextual aspects in accordance with the needs of today's Islamic society. If there is an interpretation of women who are still gender biased, Amina offers these interpretations to be reviewed so that they have a balance between the rights of men and women.
\end{abstract}

Keywords; Hermeneutic, Communication, Amina Wadud

Korespondensi: Labibul Wildan

Lumajang

mahbubghozali@gmail.com 


\section{A. PENDAHULUAN}

Pada dekade 1980-an, gerakan feminisme dalam dunia Islam mengalami perkembangan yang signifikan. Meskipun dalam dekade ini, feminisme Islam belum menampakkan diri untuk merumuskan sebuah model penafsiran (hermeneutika) feminis secara sistematik. Akan tetapi, sebagaimana gerakan pembaharuan sebelumnya, feminisme Islam lebih dahulu terjun dalam bidang exegesis, di samping penafsiran sebelumnya yang dianggapnya bersifat androsentris dan misoginis. Representasi tokoh feminis dalam bidang exegesis ini adalah Riffat Hasan. Upaya perumusan hermeneutika feminis al-Qur'an secara lebih sistematis dimulai pada awal dekade 1990. Saat itu, Riffat Hassan belum merumuskan hermeneutika feminisnya secara sistematik. ${ }^{1}$

Sementara itu, Amina Wadud Muhsin dalam Qur'an and Women memberikan hermeneutika feminisnya secara lebih sistematis. Nama Amina Wadud mulai dikenal meluas pasca ia menjadi Imam dalam Shalat Jum'at pada tanggal 18 Maret 2005. Ia bertindak sebagai imam² ${ }^{2}$ sekaligus khatib shalat Jum'at di ruangan Synod House di Gereja Katedral St. John The Divine di kawasan Manhattan, New York Amerika Serikat. $^{3}$

Dalam pendahuluannya, Amina Wadud menjelaskan panjang lebar hermeneutikanya, yang diklaimnya memiliki pendekatan holistik dalam penafsiran al-Qur'an. Meskipun metodologinya dipengaruhi hermeneutika Fazlur Rahman, terdapat beberapa inovasi tipikal feminis. Hal yang signifikan dalam hermeneutika

\footnotetext{
${ }^{1}$ Yayan Rahtikawati dan Dadan Rusmana, Metodologi Tafsir al-Qur'an (Bandung: Pustaka Setia, 2013), 474.

2 Amina Wadud berlandasakan pada kebolehan perempuan menjadi imam salat atas dasar ketika Nabi memerintahkan Ummu Waraqah untuk menjadi imam salat bagi penghuni rumahnya, karena kebolehan Ummu Waraqah bagi makmum laki-laki era Rasulullah memiliki kapasitas yang mumpuni. Alasan diperbolehkan disini karena perbandingan kedua hadis antara yang membolehkan dan melarangnya ternyata lebih kuat hadis yang membolehkannya daripada hadis yang melarangnya. Untuk melihat kasus Amina Wadud lebih jauh lihat Zaitunah Subhan, Menggagas Fiqh Pemberdayaan Perempuan (Jakarta: ElKahfi, 2008), 131-133. Dari sumber lain diterangkan bahwa Menurut Husein Muhammad dalam kitab alMajmu' karya Imam Nawawi ulasan luas atas kitab al-Muhadhdhab karya Abu Ishaq al-Shirziy di mana ada tiga ahli fiqh terkemuka yang membolehkan perempuan mengimami salat laki-laki, mereka adalah Abu Thawriy, al-Muzani, dan Ibn Jarir al-T\{abariy. Ketika Ummu Waraqah diperbolehkan Nabi untuk menjadi imam bagi penghuni rumah tersebut ada dua laki-laki tanggunganya, seorang kakek dan seorang budak, ditambah seorang budak perempuan. Ummu Waraqah mengimami kakek, budak laki-laki, dan budak perempuan tersebut.

${ }^{3}$ Apa yang dilakukan Amina Wadud, menjadi sorotan ulama dunia seperti Shaykh al-Azhar, Muhammad Sayyid al-T\{antawiy di Mesir yang merasa keberatan dengan ulah Amina Wadud tersebut. Bahkan Yusuf alQardawiy memberikan vonis tindakan tersebut tidak Islami dan bid'ah. Lihat pengantar Khaled Abou elFadhl dalam buku Amina Wadud Muhsin, Inside Gender Jihad: Women"s Reform in Islam (Oxford: Oneworld Publication, 2006), vii.
} 


\section{Labibul Wildan}

feminis ini adalah masuknya analisis gender dalam menginterpretasi al-Qur'an. Analisis gender ini dimulai sejak analisis terhadap aspek gender secara linguistik alQur'an, sampai pada analisis terhadap struktur sosial-budaya masyarakat Arab sebelum dan saat diturunkannya wahyu yang notabene patriarkis dan androsentris. Masuknya analisis gender dalam Hermeneutika al-Qur'an, menurut Nasaruddin Baidan, merupakan hal baru sejalan menguatnya gerakan feminisme dalam dunia Islam, termasuk di Indonesia. ${ }^{4}$

Penelitian ini bermaksud untuk menjelaskan langkah metodis yang dilakukan Amina Wadud dalam bukunya yang berjudul Qur'an and Woman: Rereading the Sacred Text from a Woman's Perspective. Melalui makalah ini penulis mencoba untuk menganalis ruang dalam wilayah penafsiaran Amina Wadud untuk memasukkan analisa gender dan hermeneutika feminisnya.

\section{B. PEMBAHASAN}

\section{Biografi Amina Wadud}

Amina Wadud lahir dengan nama Maria Teasley di Bethesda Maryland Amerika Serikat pada tahun 1952. Ayahnya seorang pengkhotbah Kristen Metodis. Sedangkan Ibunya keturunan budak Muslim Arab, Barbar di Afrika. Pada tahun 1972 ia mengucapkan shahadat untuk masuk Islam ${ }^{5}$ di University of Pennsylvania tempat ia belajar sampai dia menerima gelar BS pada tahun 1975 yang sebelumnya menjadi praktisi Buddish dalam waktu yang cukup singkat yaitu satu tahun. Pada tahun 1974 namanya resmi diubah menjadi Amina Wadud, yang sengaja dipilih untuk mencerminkan afiliasi agamanya.

Dia mendapat gelar MA dalam Studi Timur Dekat, gelar Ph.D dalam bahasa Arab, serta studi Islam dari University of Michigan pada tahun 1988. Selama studi, ia juga aktif belajar bahasa Arab di Universitas Amerika Kairo, kemudian dilanjutkan dengan studi al-Qur'an dan tafsir di Universitas Kairo, serta mengambil kursus filsafat di Universitas al-Azhar. Sebelum menjadi profesor Agama dan Filsafat di Virginia Commonwealth University (VCU) pada tahun 1992,

\footnotetext{
${ }^{4}$ Nasaruddin Baidan, Kesetaraan Gender dalam al-Qur'an (Jakarta: Paramadina, 1989).

${ }^{5}$ Sehingga hari itu bagi Wadud dinamakan Thanksgiving Day. Lihat Wadud, Inside Gender Jihad, 9.
} 
ia menghabiskan waktunya untuk mengajar di dua Negara yaitu Malaysia ${ }^{6}$ dan Lybia.

Setelah menulis buku "Qur'an and Women, Rereading The Sacred Text from a Women's Prespective" yang sangat monumental tersebut, Wadud mendapat banyak undangan untuk menyampaikan gagasannya tentang studi gender pada konferensi di beberapa Negara bagian Amerika Serikat, bahkan di seluruh dunia. Diantara prestasi Wadud yang lain adalah sebagai anggota istimewa di "Sister in Islam", sebuah organisasi yang didirikan oleh perempuan Muslim yang peduli dengan penindasan yang dihadapi perempuan. ${ }^{7}$ Sehingga pada tahun 2001, ia diundang oleh Colin Powel untuk menghadiri jamuan makan malam Ramadan di Gedung Putih.

\section{Kegelisahan Akademik Amina Wadud}

Melihat fenomena yang terjadi di belahan dunia Islam, Amina Wadud dihadapkan pada kegelisahan ketika melihat keterpurukan perempuan Islam di segala bidang (as a fully human agency) yang disebabkan oleh dampak kolonialisasi di dunia timur. Akan tetapi usaha untuk mengatasi problematika ini dengan model pembacaan klasik mulai berkembang. Literatur ini kemudian memainkan peranan sangat penting bahkan mengalahkan al-Qur'an yang semula menjadi sandarannya. Akibatnya studi-studi keislaman terfokus pada pemahaman literatur. Yang terjadi kemudian adalah keterputusan dari kitab orisisnil dan tujuan yang dikandungnya. ${ }^{8}$

Untuk mengatasi problematika, Amina Wadud mengklaim bahwa usahanya didasarkan pada pengembalian keterputusan dengan al-Qur'an dalam menjawab berbagai problem khususnya mengenai perempuan. Ia menganggap isu yang terkait dengan perempuan dalam al-Qur'an memiliki dua implikasi penting. Pertama, untuk menjadikan al-Qur'an terus relevan, maka penafsiran ulang harus terus dilakukan. Kedua, kemajuan peradaban tercermin dari tingkat partisipsi

\footnotetext{
${ }^{6}$ Ketika di Malaysia dia menulis buku yang pertama tentang penafsiran dan pembacaan kritis terhadap alQur'an dengan judul "Qur"an and Women, Rereading The Sacred Text from a Woman"s Prespective". Buku ini mendapat pengakuan internasional terhadap kompetensi analisis ilmiahnya.

${ }^{7}$ Organisai perempuan yang mengadakan pertemuan mingguan tersebut mengkaji otentisitas al-Qur'an dan mempromosikan tentang kesetaraan perempuan dalam Islam. Lihat Wasid dkk, Menafsirkan Tradisi \& Modernitas: Ide-ide Pembaharuan Islam (Surabaya: Pustaka Idea, 2011), 92.

${ }^{8}$ Amina Wadud, Qur'an and Woman: Rereading the Sacred Text from a Woman's Perspective (New York: Oxford University Press, 1999), xx.
} 
perempua dalam masyarakat dan pengakuan pentingnya sumberdaya perempuan. Dalam konteks Islam dan kaum muslim, pemahaman atas konsep perempuan dalam al-Qur'an yang dibangun lebih dari 1.400 tahun yang lalu menunjukkan tingkat peradapan yang maju. Jika pemahaman itu di praktekkan sepenuhnya, Islam akan menjadi kekuatan global yang mendorog pemberdayaan kaum perempuan. ${ }^{9}$

Bagi Amina Wadud, keputusannya mengkaji al-Qur'an dianggap tidak terlalu unik dibandingkan perspektif kaum feminis lain yang menghendaki pemutusan total dari masa lampau. Menurut kaum feminis, optimalisasi kemajuan terkait langsung dengan pembebasan diri dari ikatan tradisi. Dari sini, Amina Wadud menemukan arti penting al-Qur'an yang tidak terikat dengan pada waktu dan ungkapannya tentang nilai-nilai abadi. Baginya, bukan teks al-Qur'an yang membatasi perempuan, melainkan penafsiran terhadap teks itulah (yang dianggap lebih penting dari pada al-Qur'an sendiri) yang membatasi. Dalam agama lain, kaum feminis masih harus memasukkan perempuan ke dalam wacana agar mereka mendapatkan legitimasi. Akan tetapi, menurut Amina Wadud, perempuan muslim hanya perlu memahami al-Qur'an saja, dengan tidak terbelenggu oleh penafsiran-penafsiran yang eksklusif dan mengekang bila mereka ingin mendapatkan kebebasan yang tak terbantahkan. ${ }^{10}$

Disisi lain, anggapan bahwa perempuan lebih rendah atau tidak sederajat dengan laki-laki, merupakan sisi lain dari kegelisahan akademik yang ditampakkan oleh Amina Wadud. Pandangan semacam ini baginya, tidak hanya mempengaruhi kedudukan perempuan dalam masyarakat, akan tetapi juga mempengaruhi penafsiran tentang kedudukan perempuan dalam al-Qur'an. Salah satu dari keyakinan semacam ini adalah adanya perbedaan-perbedaan esensial antara laki-laki dan perempuan yang tercermin dalam penciptaan, kapasitas dan fungsi dalam masyarakat, kemudahan mencapai petunjuk serta pahala yang didapat di dalam akhirat (pembahasan tentang tema tersebut merupakan bahasan dari Qur'an and Women). ${ }^{11}$

\footnotetext{
${ }^{9}$ Ibid., xxi.

${ }^{10}$ Ibid.

11 Ibid., 7.
} 
Meskipun demikian, Amina Wadud meyakini adanya perbedaan antara laki-laki dan perempuan akan tetapi menurutnya, perbedaan tersebut tidak terkait dengan sifat-sifat dasar dan fungsi sosial antara laki-laki dan perempuan. Perbedaan ini hanya mengenai perbedaan anatomis yang telah dijelaskan dalam al-Qur'an. ${ }^{12}$

\section{Kerangka Teoritis Studi Gender Amina Wadud}

Berangkat dari kegelisahan akademik yang dialami Amina Wadud, ia pun berasumsi bahwa tafsir yang ditulis secara eksklusif oleh para mufassir mempunyai cara pandang endosentris. ${ }^{13}$ Ini disebabkan kuatnya absolutisme budaya patriarkhi yang melekat diberbagai khazanah ilmu-ilmu keislaman (khususnya tafsir dan fikih). Hal ini yang membuat Amina Wadud mengklaim bahwa objektivitas penafsiran tidak pernah bisa mencapai level yang absolut. Subjektivitas seorang mufassir selalu ada dan tidak jarang lebih dominan dalam kandungan tafsir maupun produk fikihnya. ${ }^{14}$ Karena kewenangan dalam menafsirkan teks-teks suci pada tataran praksis secara eksklusif dikuasai oleh kaum laki-laki, maka wajar saja bila ada semacam dominasi ijtihad di ruang ini. Sehingga dengan ini perempuan terus-menerus di bawah kekuatan laki-laki dan harus tunduk kepada kekuasaan mereka demi terwujudnya kehidupan domestik dan publik yang ideal. Perempuan diperlakukan sebagai anggota masyarakat kelas dua, atau lebih tragis lagi sebagai second sex. ${ }^{15}$

Subjektivitas dari yang digunakan mufasssir dalam penafsiran tentang perempuan membawa Amina Wadud dalam tiga bentuk tipologi; tradisional, reaktif, dan holistik. ${ }^{16}$ Kategori pertama, tafsir tradisional telah memberikan interpretasi-interpretasi tertentu sesuai minat dan kemampuan mufassirnya yang bisa bersifat hukum, tasawuf, gramatik, retorik, atau historis. Metodologi yang

\footnotetext{
12 Ibid., 8.

${ }^{13}$ Amina Wadud Muhsin, "Qur'an and Women" dalam Liberal Islam, Charles Kurzman (ed.), terj. Bahrul Ulum dan Heri Junaedi (Jakarta: Paramadina, 2001), 128.

14 Wadud, Qur'an and Women, 1.

${ }^{15}$ Karena sebagai masyarakat kelas dua maka pada umumnya yang melakukan tidak kekerasan atas nama agama adalah kaum laki-laki, karena mereka berpijak dari rumusan epistemologi dan cara pandang keberagamaan yang bias laki-laki bahkan keberagamaan menggunakan logika gagah dan berani untuk sebuah perjuangan kebenaran dari apa yang diperjuangkan. Pengertian ini merujuk pada potret keagamaan manusia bahwa kehadiran tafsir yang dominan adalah produk kaum laki-laki, produk kaum perempuan agaknya lenyap dan dilenyapkan oleh dominasi kaum laki-laki. Subhan, Menggagas Fiqh Pemberdayaan, 57. Bandingkan dengan Khaled Abou el-Fadl dalam Foreword "Inside The Gender Jihad" (England: Oneworld Publication, 2008), xii.

16 Wadud, Qur'an and Women, 1.
} 
digunakan bersifat atomistik, yaitu penafsiran dilakukan dengan mengupas ayat per ayat secara berurutan. Tidak ada upaya untuk menempatkan dan mengelompokkan ayat-ayat sejenis ke dalam pokok-pokok bahasan yang tertulis. Dalam hal ini Wadud menuding bahwa tafsir-tafsir tradisional itu ditulis oleh kaum laki-laki secara eksklusif. Itulah sebabnya maka hanya laki-laki dan pengalamannya saja yang direkomendasikan dalam tafsir itu. Sedangkan perempuan dengan pengalaman, visi, perspektif, keinginan, atau kebutuhannya ditundukkan pada pandangan laki-laki.

Kategori kedua, tafsir reaktif yang isinya terutama mengenai reaksi para pemikir modern terhadap sejumlah besar hambatan yang dialami perempuan yang dianggap berasal dari al-Qur'an. Persoalan yang dibahas dan metode yang digunakan seringkali berasal dari gagasan kaum feminis dan rasionalis, namun tanpa dibarengi analisis yang komprehensif terhadap al-Qur'an. Dengan demikian meskipun semangat yang dibawa adalah kebebasan, namun tidak terlihat hubungannya dengan sumber ideologi dan teologi Islam, yaitu al-Qur'an.

Kategori ketiga adalah tafsir holistik yang menggunakan metode penafsiran dan mengaitkan dengan berbagai persoalan sosial, moral, ekonomi, dan politik, termasuk isu tentang perempuan pada era modern ini. Menurut Amina Wadud tafsir model inilah merupakan metode terbaik. Dalam kategori inilah ia menempatkan karyanya. ${ }^{17}$ Teori holistik ini menawarkan metode pemahaman alQur'an yang menyatu (coherent) disebut sebagai teori hermeneutika. ${ }^{18}$

\section{Hermeneutika Komunikatif Amina Wadud}

Setelah Amina Wadud mengkritisi berbagai macam metode dan penafsiran sebelumnya, Amina Wadud menawarkan metode hermeneutika al-Qur'an sebagai

\footnotetext{
17 Ibid., 3.

18 Di sini Amina Wadud menyatakan" I attempt to use the method of Qur"anic interpretation proposed by Fazlur Rahman". Ibid., 3-4. Menurut Rahman, pertama, bahwa al-Qur'an perlu dipahami dulu dengan mengkaji suatu pernyataan dari sisi historis dan sosiologis, mengkaji konteks makro mengenai konteks sosial masyarakat saat al-Qur'an diturunkan. Kedua, mengenalisir jawaban-jawaban spesifik tersebut, dan menyatakan sebagai pernyataan-pernyataan yang memiliki tujuan sosial umum yang dapat disaring dari ayat-ayat spesifik dalam cahaya latar belakang sosio-historis dan rasio yang sering dinyatakan. Langkah yang diambil Fazlur Rahman dalam model penafsirannya di kenal dengan double movement (merumuskan visi al-Qur'an secara utuh dan kemudian menerapkan prinsip umum tersebut dalam situasi sekarang), langkah pertama adalah memulai dengan kasus konkret yang ada dalam al-Qur'an untuk menemukan prinsip umum (to find the general principle). Langkah kedua, berangkat dari prinsip umum yang digunakan sebagai acuan mendasar dalam menentukan weltanschaung dari al-Qur'an, yakni keadilan, sosial, dan ekonomi serta prinsip kesetaraan. Lihat Fazlur Rahman, Islam and Modernity, Transformation of on Intellectual Tradition (Chicago: The University of Cichago, 1981), 36.
} 
salah satu bentuk metode penafsiran untuk memperoleh kesimpulan makna suatu teks atau ayat. Dalam kerangka hermeneutika secar umum, Amina Wadud menjelaskan, seorang mufassir harus selalu menghubungkan tiga aspek dalam melakukan interpretasi: pertama, dalam konteks apa teks itu ditulis, jika kaitannya dengan al-Qur'an, maka dalam konteks apakah ayat itu diturunkan. Kedua, Bagaimana komposisi tata bahasa teks (ayat) tersebut, bagaimana pengungkapannya, apa yang dikatakanya. Dan yang ketiga, bagaimana keseluruhan teks (ayat), weltanchaung atau pandangan hidupnya. ${ }^{19}$

Corak hermeneutika yang dipilih oleh Amina Wadud dielaborasi melalui kerangka tersebut, sehingga setiap ayat yang hendak ditafsirkan dianalisa disesuaikan dengan langkah sebagai berikut: Pertama, Bagaimana konteksnya, kedua, dalam konteks pembahasan topik yang sama dalam al-Qur'an. Ketiga, menyangkut soal bahasa yang sama dan struktur sintaksis yang digunakan di seluruh bagian al-Qur'an. Keempat, menyangkut sikap benar-benar berpegang teguh pada prinsip-prinsip al-Qur'an. Dan kelima, dalam konteks al-Qur'an sebagai weltanschaung atau pandangan dunia al-Qur'an. ${ }^{20}$ Dalam menafsirkan al-Qur'an, Amina Wadud tidak hanya menggunakan metode hermeneutika saja tetapi juga menggunakan metode tafsir tradisional yaitu tafsir al-Qur'an bi al-Qur'an untuk menganalisa semua ayat-ayat yang memberikan petunjuk khusus bagi perempuan, baik yang disebutkan secara terpisah ataupun bersama dengan lakilaki. ${ }^{21}$

Tujuan Amina Wadud tersebut adalah untuk mengembalikan kandungan teks yang telah tereduksi dan terdistorsi oleh para mufassir (laki-laki), yang terjebak prejudice (prasangka), agar produk tafsir al-Qur'an tersebut mempunyai makna dalam kehidupan masyarakat modern. Prasangka yang dimaksud Amina Wadud ini mengenai bahasa dan prateks. Pembacaan dan pemahaman atas teks apapun, menurut Amina Wadud, dipengaruhi oleh prateks (prior text) dari pembaca perseorangan. Ketika pembaca perseorangan memiliki pandangan dunia tertentu dan prateks yang spesifik, menegaskan bahwa pemahamannya merupakan satu-satunya pemahaman yang mungkin atau sah, maka hal tersebut

\footnotetext{
${ }^{19}$ Wadud, Qur'an and Women, 3.

20 Ibid., 5.

21 Ibid., 4.
} 
akan mengahalangi para pembaca dari konteks yang berbeda untuk mengikuti relasa mereka sendiri dengan menyepakati teks tersebut. ${ }^{22}$

Hai sekalian manusia, bertakwalah kepada Tuhan-mu yang telah menciptakan kamu dari seorang diri, dan dari padanya Allah menciptakan isterinya; dan dari pada keduanya Allah memperkembang biakkan laki-laki dan perempuan yang banyak. dan bertakwalah kepada Allah yang dengan (mempergunakan) nama-Nya kamu saling meminta satu sama lain, dan (peliharalah) hubungan silaturrahim. Sesungguhnya Allah selalu menjaga dan mengawasi kamu. ${ }^{23}$

Dari ayat tersebut, menurut Wadud, ada beberapa kata kunci yang harus diperhatikan yakni min, nafs, zawj. ${ }^{24}$ Menurut Amina Wadud, min dalam bahasa Arab memiliki dua fungsi dasar yakni bisa digunakan sebagai kata depan (beemakna dari), yang menunjukkan penarikan suatu hal dari hal lain; selain itu min juga bisa menunjukkan kesamaan sifat/kualitas.

Pengunaan min dalam arti kesamaan sifat/kualitas, menurutnya, seperti yang dilakukan al-Zamakhshariy ketika menafsirkan ayat tersebut dengan makna manusia diciptakan menurut/dari jenis yang sama dengan nafs yang tunggal, dan bahwa zawj diambil dari nafs tersebut. Di samping itu, ayat lain tentang pokok bahasan ini (al-A'raf: 189; al-Zumar: 6) menyatakan bahwa Allah ja'ala dari nafs itu zawj-nya. Kata ja'ala, yang berarti menciptakan sesuatu dari sesuatu yang lain, membuat kata min mengandung arti dari, yaitu penarikan. Arti kata min ini menimbulkan pemikiran bahwa manusia pertama yang diciptakan (seorang lakilaki) adalah lengkap, sempurna dan mulia. Sedangkan manusia kedua yang diciptakan (seorang perempuan) tidaklah sama dengan yang pertama, sebab dia

\footnotetext{
22 Ibid., 5.

23 Mujamma' al-Malik Fahd li Tiba'at al-Mushaf, al-Qur'an dan Terjemahnya (Madinah: Mujamma' al-Malik Fahd li Tiba'at al-Mushaf, $1421 \mathrm{H}), 114$.

24 Sebenarnya Amina Wadud menyatakan ada empat kata kunci yang perlu diperhatikan dari ayat di atas, yakni min, nafs, zawj dan ayat. Akan tetapi, Amina Wadud sepertinya tidak berhati-hati dalam mengutip ayat al-Qur'an, sebab dalam surah al-Nisa' ayat 1 tidak ada kata-kata ayat. Seharusnya surah al-Nisa' ayat 1 adalah sebagaimana yang penulis cantumkan di atas namun Amina Wadud menuliskan sebagai berikut; $W a$ min ayatihi an khalaqakum min nafs wahidah wa khalaqa minha zawjah wa bathth minhuma rijalan kathiran wa nisa'an (4:1). And min His ayat (is this:) that He created You (humankind) min a single nafs, and created min (that nafs) its zawj, and from these two He spread (through the earth) countless men and women. (4:1). Wadud, Qur'an and Woman, 17.
} 
diambil dari yang sempurna sehingga merupakan derivasi saja dan ia tentunya tidak sesempurna yang pertama. ${ }^{25}$

Begitu juga, menurut Amina Wadud, terjemahan al-Qur'an dalam bahasa Inggris mengartikan setiap kata min dalam ayat yang telah disebutkan dengan from (dari), sehingga mengesankan kemungkinan yang lain. Namun, berbagai penafsiran terhadap kata min ini tidak memperjelas makna yang paling signifikan dari kata nafs dan zawj dalam surat al-Nisa' ayat 1.

Kata yang kedua adalah nafs. Kata ini, menurut Amina Wadud, digunakan secara umum dan teknis. Walaupun secara uum kata ini diterjemahkan sebagai diri, namun al-Qur'an tidak pernah menggunakannya untuk menunjuk pada diri makhluk selain manusia. Secara teknis, menurut Amina Wadud, kata nafs dalam al-Qur'an merujuk pada asal semua manusia secara umum. Meskipun manusia berkembang biak dimuka bumi dan membentuk bermacam-macam negara, suku dan bangsa yang berlainan bahasa dan warna kulit, namun mereka semua berasal dari sumber yang sama. ${ }^{26}$

Secara gramatikal, nafs menurut Amina Wadud berjenis feminin dan merupakan anteseden dari kata sifat atau kata kerja feminin. Namun, secara konseptual, nafs tidak maskulin maupun feminin, dan menjadi bagian esensial dari setiap orang, laki-laki maupun perempuan. Karena itu, kata ini juga dapat mempunyai anteseden maskulin. ${ }^{27}$

Ia kemudian mengutip pendapat Fazlur Rahman dalam al-Qur'an, kata nafs - yang kemudian dalam filsafat dan sufisme Islam diartikan jiwa, sebuah substansi yang terpisah dari tubuh - kebanyakan merujuk pada dirinya sendiri (laki-laki maupun perempuan), dan jamaknya (anfus) pada diri mereka sendiri, meskipun dalam konteks ia merujuk pada manusia atau manusia batiniah, yakni realitas hidup manusia-yang tak terpisah atau terlepas dari tubuh. Sebenarnya, tubuh yang mempunyai pusat kehidupan dan kecerdasanlah yang merupakan identitas batiniah atau personalitas manusia. ${ }^{28}$

Setelah menjelaskan makna nafs, Amina Wadud menjelaskan lafad penting lainnya yakni zawj. Menurutnya, sebagai istilah umum, zawj digunakan dalam al-

\footnotetext{
25 Ibid., 18.

26 Ibid., 19.

27 Ibid.

${ }^{28}$ Lihat Fazlur Rahman, Major Themes in the Qur'an (Chicago: Bibliotheca Islamica, 1980), 112.
} 
Qur'an untuk arti teman, pasangan, atau kelompok dan bentuk jamaknya, azwaj, digunakan untuk merujuk pada bagian kedua dalam penciptaan manusia, yang diketahui sebagai Hawa. Namun menurut Amina Wadud, secara gramatikal, zawj adalah maskulin, dan merupaka anteseden dari kata sifat dan kata kerja maskulin. Secara konseptual, kata ini tidak maskulin maupun feminim, dan al-Qur'an menggunakannya untuk merujuk pada tumbuh-tumbuhan (al-Rahman: 52) dan bintang (Hud: 40), disamping juga kepada manusia. ${ }^{29}$

Amina Wadud menyatakan bahwa, informasi yang didapat mengenai penciptaan zawj lebih sedikit dibandingkan tentang penciptaan nafs yang pertama. Al-Qur'an hanya mengatakan dua hal tentang penciptaan zawj, yakni min nafs yang pertama, dan zawj yang berhubungan dengan nafs itu (al-Nisa':1; al-A'raf: 189; alZumar: 6). Menurutnya, disebabkan karena penjelasan yang minim ini, para mufassir seperti al-Zamakhshariy dan yang lainnya mengandalkan kisah injil yang menyatakan bahwa Hawa diciptakan dari ( $\mathrm{min}$ ) tulang rusuk atau pinggang Adam. ${ }^{30}$

Ketiadaan rincian tersebut menurut Amina Wadud disebabkan, pertama, pembaca sudah memiliki rincian penjelasan untuk memahami sebuah kisah sehngga rincian penjelasan lainnya tidak diperlukan. Kedua, rincian penjelasan ini tidak penting bagi poin yang sedang disebutkan al-Qur'an pada waktu tertentu. Ketiga, al-Qur'an menunjuk kepada sesuatu yang ghaib, yang tidak terjangkau oleh bahasa manusia. ${ }^{31}$

Zawj menurut Amina Wadud, sebagai salah satu dari dua hal yang berpasangan, yang sangat penting dalam penuturan al-Qur'an tentang penciptaan, sebagimana Firman Allah yang artinya: Dan segala sesuatu Kami ciptakan berpasang-pasangan supaya kamu mengingat kebesaran Allah. ${ }^{32}$

Ayat ini mengindikasikan dualisme dalam penciptaan yang merupakan sebuah ciri penting dari segala sesuatu yang diciptakan. ${ }^{33}$ Menurut

\footnotetext{
29 Wadud, Qur'an and Women, 20.

30 Meskipun banyak hadis yang menyebutkan hal ini, menurut Amina Wadud, jangan sampai dilupakan kisah dalam hadis tersebut semuanya memiliki rantai tunggal dalam sanadnya (ahad), sehingga mengurangi kekuatannya. Untuk analisis lebih terperinci tentang hal ini, lihat Riffat Hassan, "Made from Adam's Rib: The Women's Creation Question" dalam al-Mushir Theological Journal of the Christian Study Center, Rawalpindi, Pakistan, Auntumn 1985, 124-156.

31 Wadud, Qur'an and Women, 20.

32 Mujamma' al-Malik Fahd, al-Qur'an dan Terjemahnya, 862.

33 Wadud, Qur'an and Women, 20.
} 
penggunaannya, kata zawj menurut Amina Wadud, suatu pasangan terdiri atas dua hal yang berkoeksistensi dalam satu realitas dan keduanya mempunyai beberapa perbedaan dalam hal sifat, ciri dan fungsi. Namun, kedua bagian yang kagruen ini saling sesuai satu sama lain dan merupakan suatu kesatuan. Keberadaan salah satu dari pasangan ii secara semantik menunjukkan keberadaan yang lainnya dan berdiri diatas hubungan keberpasangan ini. Seorang laki-laki hanyalah seorang suami bila dilihat dari sudut pandang seorang istri. Dalam dunia nyata, eksistensi dari salah satu pasangan bergantung pada yang lainnya. Begitulah pasangan menurut al-Qur'an bagi Amina Wadud. ${ }^{34}$

Mengenai penciptaan, ungkapan segala sesuatu diciptakan berpasangan berarti bahwa pasangan dari tiap-tiap benda ciptaan adalah bagian dari rencana benda itu. Sebagaimana Firman Allah yang artinya: Maha suci Tuhan yang telah menciptakan pasangan-pasangan semuanya, baik dari apa yang ditumbuhkan oleh bumi dan dari diri mereka maupun dari apa yang tidak mereka ketahui. ${ }^{35}$

Setiap benda yang diciptakan menurut Amina Wadud, bergantung pada zawj-nya. Dalam ketergantungan ini, penciptaan kedua orang tua pertama secara azali dan mutlak saling terkait satu sama lain. Sehingga keduanya sama-sama penting. ${ }^{36}$

Walaupun al-Qur'an menegaskan bahwa manusia segaja diciptakan dalam pasangan laki-laki dan perempuan (Fatir: 11; al-Najm: 45; Ali Imran: 36), namun menurut Amina Wadud, al-Qur'an tidak memberikan karekteristik yang tegas bagi tiap-tiap bagian pasangan. Meskipun dalam al-Qur'an Allah menjelaskan fungsi melahirkan bagi perempuan (Fatir: 11; al-A'raf: 189; al-Ra'd: 8), namun semua fungsi lain yang berkaitan dengan pengasuhan dan perawatan anak (jika benarbenar disebutkan dalam al-Qur'an) tidak pernah digambarkan sebagai karakteristik penting yang diciptakan untuk perempuan. Dengan demikian, menurut Amina Wadud, keterangan al-Qur'an hanya mengacu pada fungsi biologis ibu, bukan pada persepsi psikologis dan budaya pengasuhan. ${ }^{37}$

Femininitas dan maskulinitas menurut Amina Wadud, bukanlah karakteristik bawaan yang tertanam dalam sifat azali perempuan dan laki-laki.

\footnotetext{
34 Ibid.

35 Mujamma' al-Malik Fahd, al-Qur'an dan Terjemahnya, 710.

36 Wadud, Qur'an and Women, 21.

37 Ibid.
} 
Kedua konsep ini tidak dibahas atau disinggung oleh al-Qur'an. Keduanya adalah karakteristik buatan yang diterapkan pada perempuan dan laki-laki berdasarkan faktor-faktor yang secra kultural telah ditetukan mengenai bagaimana tiap-tiap jenis kelamin mesti berfungsi. Menurut al-Qur'an, pasangan laki-laki dan perempuan - sebagai kesatuan yang penting dalam hubungan kemanusiaan berfungsi pada tataran fisik, sosial, maupun moral. ${ }^{38}$

Manurut Amina Wadud dalam kesimpulannya atas penafsiran ayat diatas (al-Nisa':1), ayat tersebut menggambarkan struktur tatanan sosial yang tercipta. Ayat ini menurutnya juga menjelaskan asal dari seluruh manusia adalah nafs yang satu, yang merupakan bagian dari suatu sitem kesatuan-pasangan, nafs dan zawj. Dalam ayat ini, penggunaan kata laki-laki dan perempuan berarti bahwa manifestasi lahiriah dari realitas keberpasangan yang penting ini dilipatgandakan dan berkembang biak. 39

\section{KESIMPULAN}

Pelajaran penting yang dapat kita ambil dari pemikiran Amina Wadud adalah bahwa ia menawarkan metodologi baru yang lebih aplikatif dalam menafsirkan ayatayat al-Qur'an yang berhubungan dengan keadilan gender. Metode tersebut layak kita katakan sebagai hermeneutika komunikatif. Hal ini disebabkan karena reaktualisasi Amina Wadud tentang keberadaan perempuan yang mengalami perlakukan kurang baik yang diakibatkan oleh penafsiran yang sangat tekstual terhadap ayat-ayat yang berbicara tentang perempuan. Amina Wadud menginginkan perempuan dalam Islam ditempatkan setara dengan laki-laki, dengan melihat aspek kontekstual sesuai dengan kebutuhan masyarakat Islam sekarang ini. Jika ada interpretasi tentang perempuan yang masih bias gender, maka Amina menawarkan tafsir tersebut dikaji ulang agar memiliki nilai keseimbangan antara hak laki-laki juga perempuan.

Amina Wadud ditempatkan sebagai pemikir Islam kontemporer yang telah menggunakan metode hermeneutika untuk menafsirkan ayat-ayat yang berbicara tentang perempuan. Amina telah menawarkan satu metode berpikir yang disebut hermeneutika feminis (gender) yang bertujuan untuk memperbaiki kedudukan perempuan dalam kehidupan sosial, politik dan hukum. Meskipun ada beberapa hal yang perlu dikritisi, akan tetapi pemikiran Amina Wadud juga dapat dijadikan bahan

38 Ibid.

39 Ibid. 
pertimbangan untuk melihat kondisi perempuan yang masih mengalami diskriminasi, misalnya ada pemahaman bahwa perempuan tidak boleh bekerja di ranah publik, tidak boleh ke Mesjid, tidak boleh sekolah, maka pemikiran ini harus dihilangkan, agar kedudukan perempuan setara dengan laki-laki.

\section{DAFTAR PUSTAKA}

Baidan, Nasaruddin. Kesetaraan Gender dalam al-Qur'an. Jakarta: Paramadina, 1989.

Hassan, Riffat. “Made from Adam's Rib: The Women's Creation Question” dalam al-Mushir Theological Journal of the Christian Study Center, Rawalpindi, Pakistan, Auntumn 1985.

Kurzman, Charles (ed.). Liberal Islam. terj. Bahrul Ulum dan Heri Junaedi. Jakarta: Paramadina, 2001.

Mujamma' al-Malik Fahd li Tiba'at al-Mushaf. al-Qur'an dan Terjemahnya. Madinah: Mujamma' al-Malik Fahd li Tiba'at al-Mushaf, $1421 \mathrm{H}$.

Rahman, Fazlur. Islam and Modernity, Transformation of on Intellectual Tradition. Chicago: The University of Cichago, 1981.

Rahman, Fazlur. Major Themes in the Qur'an. Chicago: Bibliotheca Islamica, 1980.

Rahtikawati, Yayan dan Dadan Rusmana. Metodologi Tafsir al-Qur'an. Bandung: Pustaka Setia, 2013.

Subhan, Zaitunah. Menggagas Fiqh Pemberdayaan Perempuan. Jakarta: El-Kahfi, 2008.

Wadud, Amina. Inside Gender Jihad: Women"s Reform in Islam. Oxford: Oneworld Publication, 2006.

Wadud, Amina. Qur'an and Woman: Rereading the Sacred Text from a Woman's Perspective. New York: Oxford University Press, 1999.

Wasid dkk. Menafsirkan Tradisi \& Modernitas: Ide-ide Pembaharuan Islam. Surabaya: Pustaka Idea, 2011. 